\title{
Clinical management of multiple mesial and distal canals in mandibular first molars- A case report
}

\author{
Dr. Muktishree Mahendra, Dr. Santosh Kumar Singh, Dr. Vartul \\ Dwivedi, Dr Manas Gupta \\ Asst. Professor, Dept of Conservative Dentistry \& Endodontics People Dental Academy, Bhanpur Bhopal (M.P) \\ Asst. Professor, Dept of Conservative Dentistry \& Endodontics People Dental Academy, Bhanpur Bhopal (M.P) \\ Asst. Professor, Dept of Conservative Dentistry \& Endodontics People Dental Academy, Bhanpur Bhopal (M.P) \\ Asst. Professor, Dept of Oral Medicine \& Radiology Rishiraj College of Dental Sciences \& Research Centre Gandhinagar, \\ Bhopal (M.P.)
}

\begin{abstract}
Thorough cleaning and shaping and followed by three-dimensional obturation is secret to successful clinical endodontics. Therefore, it is imperative that aberrant anatomy should be identified before and during root canal treatment. Multiple case reports of aberrant canals morphology in the mesial root of mandibular first molar have been documented. However, fewer studies have discussed the occurrence of a third distal canal in distal root of mandibular molars. The incidence of middle distal canal is much lower than that of middle mesial canal. This article presents the two rare case reports describing of multiple canals in mandibular first molars i.e 3 distal canals in one case report and 3 mesial canals in another.

Keywords: Endodontics, middle distal, middle mesial
\end{abstract}

\section{Introduction-}

There have been numerous studies describing the morphology of teeth, including mandibular first molars. In 1974, Vertucci and William, described the presence of independent middle mesial canal in mandibular first molar. And after that unusual anatomy is associated with mandibular first molar. Various case reports have been published with the finding of middle mesial canal, but very few describe three independent canals, indicating a rare anatomical configuration. Additionally, a very rare occurrence reported by Stroner et al (1984) and Beatty and Iterian (1987) was a third canal in the distal root. The purpose of this article is to report the successful treatment of additional middle mesial and distal canals in a mandibular molar.

\section{Case Report-}

Case 1

40 yrs old patient reported with complain of pain in lower right back region since 2 months. His medical history was non-contributory. Clinical examination revealed deep proximal caries with 46 . Tooth was tender to vertical percussion. Intraoral periapical radiograph showed extensive proximal caries involving pulp in 46 (Fig1). There was widening of periodontal ligament space in relation to both the roots. Root canal treatment was advised in relation to 46 .

Endodontic treatment was initiated in 46 . All carious tissue was removed, and an adequate endodontic access was made in 46 under operating microscope. The pulp chamber floor showed five canal orifices mesiolingual, mesiobuccal, distobuccal, middle distal and distolingual (Fig 2). Working length was determined (Fig 3). All canals were cleaned, shaped with conventional step back technique. Copious irrigation was done with $2.5 \% \mathrm{NaOCl}$ alternate with Normal saline. Calcium hydroxide was used as an intracanal medicament and cavity was sealed with temporary restorative material. Patient was recalled after one week, and when tooth was asymptomatic and obturation( Fig4,5) is carried out by lateral condensation done.

\section{Case 2}

A 18 yr old patient reported with the complain of pain in lower right back region of the jaw from last two days. He gave the history of pain on chewing. Patient also complained of pain especially on consumption of hot and cold foods .Clinical examination revealed deep proximal caries with 46. Intraoral periapical radiograph of 46 (Fig 2) showed extensive proximal caries involving pulp and periodontal ligament widening of distal root. Endodontic treatment was advised.

Adequate anaesthesia was obtained and the chamber accessed. As the negotiation of canals began with a no. 10 file, a third canal was found in the mesial root between the mesiolingual and mesiobuccal canals. Working length was then determined (Fig7). After the instrumentation of the cervical third of the root canals, a dental operating microscope was used to confirm the existence of the five root canals. Following cleaning, 
shaping and final irrigation with $\mathrm{NaOCl}$ alternate with EDTA, the canals were dried with paper points and an intracanal dressing with calcium hydroxide was applied for 4 days. In the second visit, the calcium hydroxide intracanal dressing was removed, the master cone fit was checked, and the root canals were dried with absorbing paper points and obturated with gutta percha points (Fig 8).

\section{Discussion}

It has been discussed and demonstrated in literatures that mandibular molars manifest variations of root canal morphology. Vertucci and William ${ }^{1}$ in 1974 described the presence of an independent middle mesial canal in mandibular first molar. Incidence of middle mesial canal is $1-15 \%{ }^{2}$. Additionally, Stroner ${ }^{3}$ et al and Batty \& Interian ${ }^{4}$ have reported a third canal located in the distal root of mandibular molar. According to the literature the incidence of third distal canals is $0.6 \%{ }^{4}$ which was found to be much lower than that of in the mesial root.

Pomeranz et $\mathrm{al}^{5}$ has classified Middle Mesial canal into three morphologic categories; fin, confluent and independent. According to their classification, an independent canal implies the canal originated as a separate orifice and terminated as a separate foramen, and only two cases were identified as independent. In this case report 3 mesial canals that were independent throughout their course in the root and were confirmed by well angulated intraoral periapical radiographs. The presence of three independent canals, presents itself as a rare anatomic variant. Distal root has three distinct canals in distal root. Fabra - Campos ${ }^{6}$ reinforced the importance of an accurate clinical evaluation of a possible fourth or fifth root canal to ensure success of endodontic treatment. Vertucci ${ }^{7}$ and De Grood and Cunningham ${ }^{8}$ reported that a considerable number of failures could be assigned to anatomical variations, such as the presence of canals not usually found. Therefore, the correct location, instrumentation and obturation of all canals are indispensable procedures.

In most of the cases, middle/extra canals are hidden by a dentinal projection in the mesial and distal aspect of pulp chamber walls, and this dentinal growth is usually located between the two main canals. Ultrasonic systems provide a breakthrough for exploring and identifying the extra canals and also eliminate the bulky head of the conventional hand piece that frequently obstructs the vision ${ }^{9}$. The detection of additional root canals requires careful examination of the pulpal floor with a sharp explorer, and better visualization using an operating microscope are all important aids in the detection. The use of dental operating microscope provides enhanced lighting and visibility and identifies subtle colour changes, better understanding of floor map, fine instrumentation, coaxial illumination, and magnification. Carvalho and Zuolo ${ }^{10}$ described the usefulness of microscopes in the accurate location of root canal orifices, which may substantially improve treatment outcomes.

Radiographic examination using intraoral periapical views is important for the evaluation of the canal configuration. Well-angulated periapical films should be taken with cone-directed straight-on, mesiooblique, and disto-oblique; this technique often reveals and clarifies the three dimensional morphology of the tooth.

\section{References}

[1]. Vertucci FJ, Williams RG. Root canal anatomy of the mandibular first molar. JNJ Dent Assoc 1974; 48:27-8.

[2]. Goel NK, Gill KS, Taneja JR. Study of root canals configuration in mandibular first permanent molar. J Indian Soc Pedod Prev Dent $1991 ; 8: 12-4$.

[3]. Stroner W, Remeikis N. Carr G. Mandibular first molar with three distal canals. Oral Surg 1984:54:554-7.

[4]. Beatty R, Interian C.A. Mandibular first molar with five canals: reported a case. JADA; 111:769-71.

[5]. Pomeranz HH, Eidelman DL, Goldberg MG. Treatment considerations of the middle mesial canal of mandibular first and second molars. J Endod 1981;7:565

[6]. Fabra-Campos CH. Unusual root anatomy of mandibular first molars. J Endod 1985; 11: 568-72.

[7]. Vertucci FJ. Root canal anatomy of the human permanent teeth. Oral Surg Oral Med Oral Pathol 1984; 58: 589-99.

[8]. De Grood ME, Cunningham CJ. Mandibular molar with 5 canals: report of a case. J Endod 1997; $23: 60-2$.

[9]. Gorduysus MO, Gorduysus M, Friedman S. Operating microscope improves negotiation of second mesiobuccal canals in maxillary molars. J Endod 2001; 27:683-6.

[10]. Carvalho MC, Zuolo ML. Orifice locating with a microscope. J Endod 2000; 26: 532-4. 


\section{IMAGES}

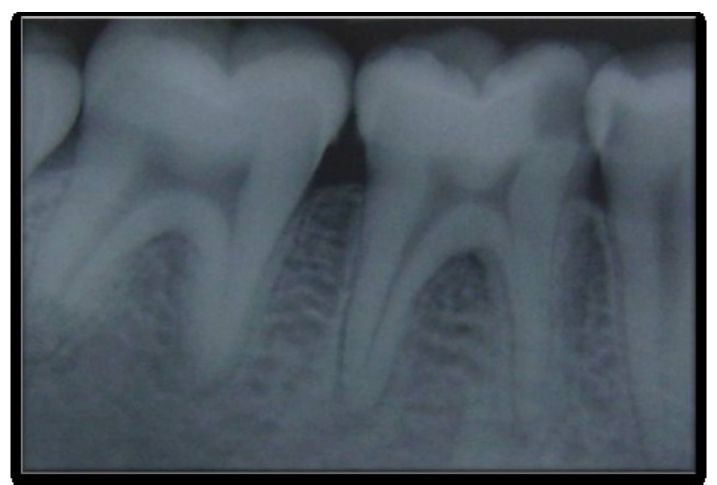

Fig 1 Diagnostic IOPA revealing deep caries and periodontal widening in 46

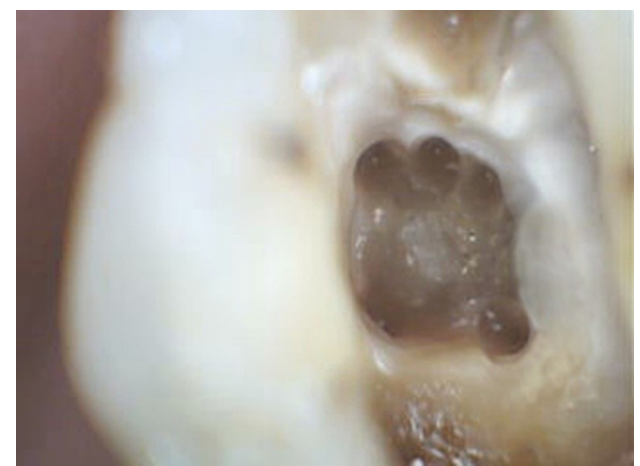

Fig 2 Clinical view of three distal canals

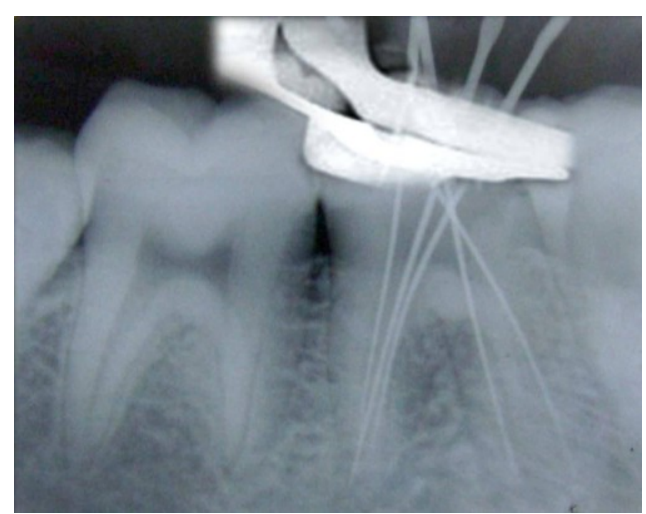

Fig 3 Working length radiograph depicting five canals in 46

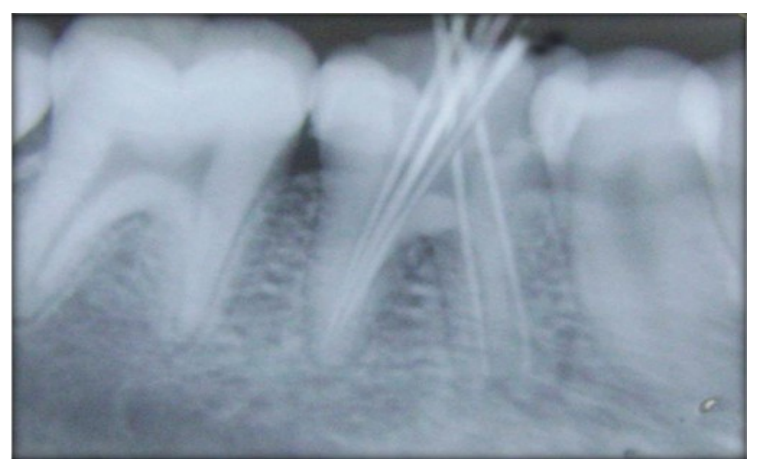

Fig 4 Master cone fit radiograph in 46 


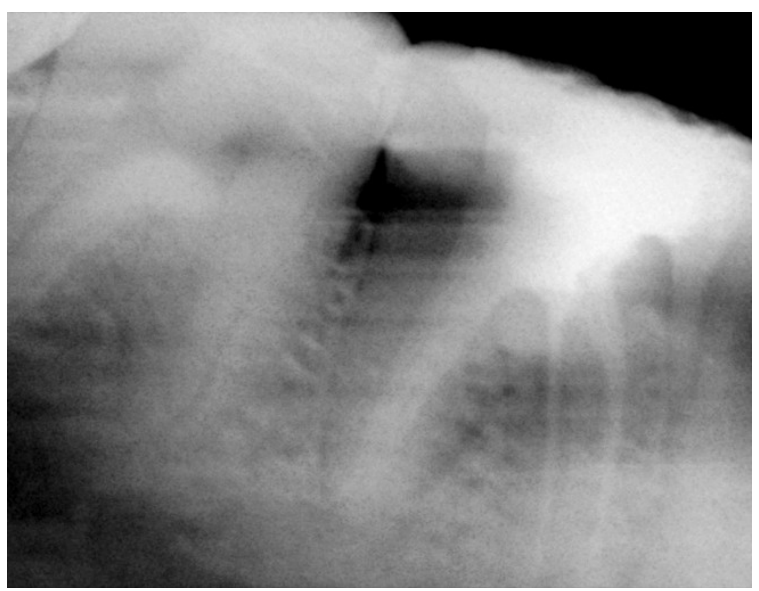

Fig 5 Obturation radiograph

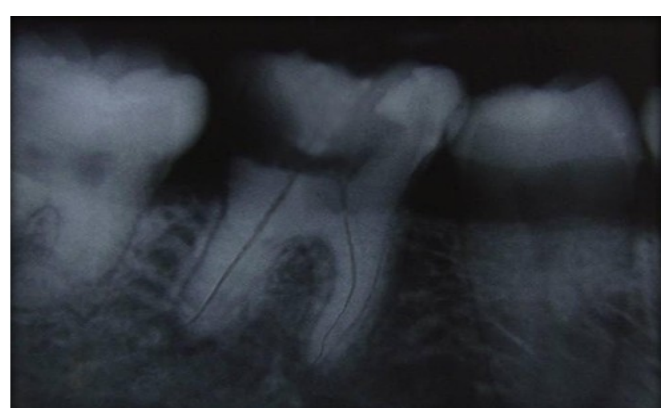

Fig 6 Preoperative IOPA revealing proximal caries and periodontal widening in 46

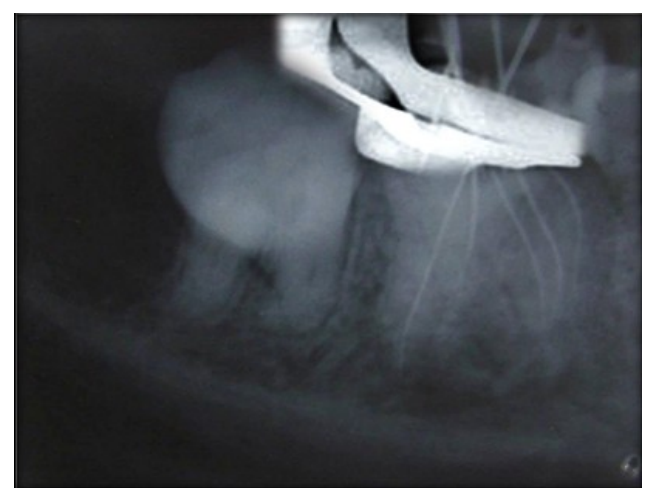

Fig 7 working length radiograph with 5 mesial\&2distal canals

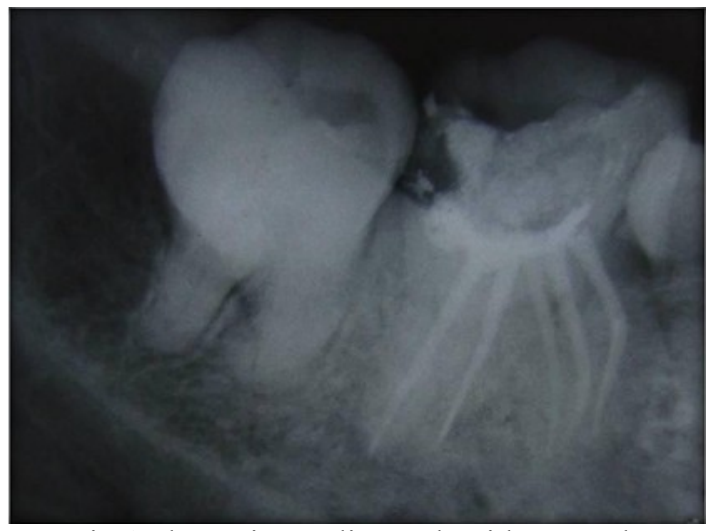

Fig 8 obturation radiograph with 5 canals 